\title{
Human resource strategies towards employee's engagement practice and involvement - A study of ICICI bank
}

\author{
Mrs. K. Swarnalatha \\ University of Madras, Chennai, India.
}

\begin{abstract}
Human resource management is an important phenomenon which encompass the very important role and responsibilities of any organization especially in the service sectors, the changing context in the economy after globalization accentuated the importance of quality of service in the banking sector became very crucial as the globalization has demolish the monopoly of the public sector banks, in this context the role and responsibilities of the human resource management on the banking obtained special consideration, against this backdrop the present study examined the human resource management strategy adopted in ICICI banks in order to engage the employees at the optimum level to unleash the good quality of service, the study conducted among the ICICI human resource managers and mangers across Chennai, the study found that various innovative options have been followed by the managers to make the employees to render their good output thereby ensure the good quality of service to the customers.
\end{abstract}

Key words: Bank, Employees, Human Resource, Management, Strategies.

\section{Introduction}

Human Resource Development has assumed considerable importance in the recent years, be it business organization or a bank or an office, the development of human resource is necessary for its efficient and effective working. In an evolutionary process when developing economy struggles to attain higher levels of living it can hardly overlook the need of developing its human resources to meet the bigger and new challenges of raising the quality of the masses. The concept of HRD deals with the improvement of human quality in general and development of human skills, standards, comprehensions and application in the production enterprises in particular. As such, HRD has become an important programme of all organizations not only for enhancing the production efficiency/ productivity has also to bring about qualitative improvement among the workers at different levels (Arthur, J.B. 1994).The importance of HRD heightened into extreme prominence as the service industries dominate the all the spheres of activities in the economy, banking is one among the important component of the activity, growing demand for the financial transaction urged the need for effective and efficient service of the banks so these elements accentuated the optimum utilization of the available resources for better outcome, thus, human resource management in the banking sector is key for good service delivery. The present study introspect the HRD strategies towards employee engagement practices and Involvement in ICICI banks in order to map out the HRD involvement to effectively utilize the employees productivity for the good service delivery.

\section{Banking industry in India}

Indian Banking has come from a long way from being a sleepy business organization to a highly proactive and dynamic entity. This transformation has been brought by the liberalization and economic reforms that allowed Banks to explore new business opportunities. In the economic system, banks play a very important role as they have the power of creating credit for the businessmen and general public for various purposes. The Banking Industry was once a simple and reliable business that took deposits from investors at a lower interest rate and loaned it out to borrowers at a higher rate. However deregulation and technology led to a revolution in the banking industry that saw it transformed. (Kao, B. Prabhakar 1993), Today when banks offer loans \& related products at a lower interest rate, it enhances the growth prospects of the economy and vice-versa. This has now become instrumental in the development of World Economy. Banks have become global powerhouses that have created even more complex products that involves risk and securitization. Through technological development, banking services have become available 24 hours a day, 7 days a week through ATMs, online banking and electronically enabled exchanges where everything from stocks to currency can be traded. At the beginning of the 21 st century, the biggest banks in the industrial world have become complex financial organizations that offer a wide range of services to international markets and control billions of dollars in cash and assets. Supported by the latest technology, banks are working to identify new business niches, to develop customized services, to implement innovative strategies and to capture new market opportunities. With further globalization, consolidation, deregulation and diversification of the financial industry, the banking sector has become even more complex. Technology, deregulation and liberalization have reinforced market competition, 
locally and internationally. Banks now have significant operations beyond their domestic borders and are handling a large amount of business and millions of non-resident clients across the globe. In the process, large, internationally active financial institutions with complex risk profiles have grown in size. Other domestic banks and institutions are also forging stronger cross-border linkages by acquiring customers abroad. Three related changes were also important.

\section{Indian banking scenario}

The banking scenario in India has already gained all the momentum, with the domestic and international banks gathering pace. The focus of all banks in India has shifted their approach to 'cost', determined by revenue minus profit. This means that all the resources should be used efficiently to better the productivity and ensure a win-win situation. To survive in the long run, it is essential to focus on cost saving. Previously, banks focused on the 'revenue' model which is equal to cost plus profit. Post the banking reforms, banks shifted their approach to the 'profit' model, which meant that banks aimed at higher profit maximization. Currently, India has 96 scheduled commercial banks (SCBs), 27 public sector banks (that is with the Government of India holding a stake), 31 private banks (these do not have government stake; they may be publicly listed and traded on stock exchanges) and 38 foreign banks. They have a combined network of over 53,000 branches and 49,000 ATMs. According to a report by ICRA Limited, a rating agency, the public sector banks hold over 75 percent of total assets of the banking industry, with the private and foreign banks holding $18.2 \%$ and $6.5 \%$ respectively. The escalation in the bank operation unleash lot of challenges to the bankers especially the pressures on the employees of banks around the world have been manifold across financial system deregulation, entry of new players and products with advanced technology, globalization of financial markets, changing demographics of customer behaviour, consumer pressure for wider choice and cheaper service, shareholder wealth demands, shrinking margins in this context the role of human resource management for optimum utilization is became very important phenomenon in the same line private bank participation in the banking industries have been increasing predominantly, thus, the functional operations of the HR strategies to utilize the productivity of the employees thereby ensure the good quality of service heightened into indispensible tool in the current scenario.

\section{Human resources management practices in banking sector}

Human Resource Development has assumed considerable importance in the recent years, be it business organization or a bank or an office, the development of human resource is necessary for its efficient and effective working. In an evolutionary process when developing economy struggles to attain higher levels of living it can hardly overlook the need of developing its human resources to meet the bigger and new challenges of raising the quality of the masses (Kool, Reeta and Saksena, N. K. 1989) The concept of HRD deals with the improvement of human quality in general and development of human skills, standards, comprehensions and application in the production enterprises in particular. As such, HRD has become an important programme of all organizations not only for enhancing the production efficiency/ productivity has also to bring about qualitative improvement among the workers at different levels (Abraham E.S.J. 1988). In the economic system, banks play a very important role as they have the power of creating credit for the businessmen and general public for various purposes. The Banking Industry was once a simple and reliable business that took deposits from investors at a lower interest rate and loaned it out to borrowers at a higher rate. However deregulation and technology led to a revolution in the banking industry that saw it transformed. Today when banks offer loans \& related products at a lower interest rate, it enhances the growth prospects of the economy and vice-versa. This has now become instrumental in the development of World Economy. Banks have become global powerhouses that have created even more complex products that involve risk and securitization in models that only research scholars can understand. Through technological development, banking services have become available 24 hours a day, 7 days a week through ATMs, online banking and electronically enabled exchanges where everything from stocks to currency can be traded. At the beginning of the 21 st century, the biggest banks in the industrial world have become complex financial organizations that offer a wide range of services to international markets and control billions of dollars in cash and assets. Supported by the latest technology, banks are working to identify new business niches, to develop customized services, to implement innovative strategies and to capture new market opportunities. With further globalization, consolidation, deregulation and diversification of the financial industry, the banking sector has become even more complex. Technology, deregulation and liberalization have reinforced market competition, locally and internationally(Agarwal Ashok and Udai Pareek.1997)Banks now have significant operations beyond their domestic borders and are handling a large amount of business and millions of non-resident clients across the globe. In the process, large, internationally active financial institutions with complex risk profiles have grown in size. Other domestic banks and institutions are also forging stronger cross-border linkages by acquiring customers abroad. 


\section{Conceptual illustration of the study}

The term Human Resource Development (HRD) has gained wide currency in India especially since the early 1980s. In fact, contrary to the trend elsewhere, the buzz word in people management in India is HRD and not HRM“ (Saini, 2000,35) HRD is often equated with Training and in many organizations, the Training alone is called the HRD department (Rao, 1999, 11) as always Dynamic employees are essential for any organization that would like to be dynamic and growth oriented. Employees who are competent, motivated, proactive and have a high activity level can be considered as dynamic employees along with the several other qualities. -Human resource development in the organizational context is a process by which the employees of an organization are helped in a continuous, HRD in the organizational context is a process through which employees and group of employees in the organization are assisted in realizing their full potential in the present and future jobs, thereby creating a culture conducive for the organization to achieve its objective effectively. This process is continuous and planned identifying key employee and organizational outcomes that were likely influenced by innovative human resource practices(AgarwalTaniya .2002) and the basic purpose of HRM is to improve the productive, contribution of people to the organization (Moorthy K.N. 1994Mc.Cauley, Cynthia D.2005). The importance of HRM strategy heightened into indispensable level in the banking industries since Banking industry in our country is fast developing and it has been assigned a crucial role in country's economic development. Branch expansion and employment generation has touched new heights in this industry. In view of its expanding role in the national economy and huge public funds at the disposal of banks, it is the need of the hour for banking industry in general and rural banks in particular to adjust to their operation (Yatoo 2000). Thus, the effective management must ensure that the efforts of personnel are channeled and guided on productive lines (Rao, 1993).Thus, the present study made asses the HRM strategy to involve the bank personnel to ensure the good quality of service in ICICI bank.

\section{Historical Background of ICICI Bank:}

The history of Industrial Credit \& Investment Corporation of India (ICICI) shows that it was formed in 1955 by the initiative of the World Bank, the Government of India and representatives of Indian industry. The principal objective of ICICI was to create a development financial institution for providing medium-term and long-term project financing to Indian businesses. In the 1990s, ICICI transformed its business from a development financial institution offering only project finance to a diversified financial services group offering a wide variety of products and services, both directly and through a number of subsidiaries and affiliates like ICICI Bank. In 1999, ICICI became the first Indian company and the first bank or financial institution from nonJapan Asia to be listed on the NYSE. Due to the changing business environment and after the adoption of liberalization, ICICI considered various corporate restructuring alternatives in the context of the emerging competitive scenario in the Indian banking industry, and the move towards universal banking. The managements of ICICI and ICICI Bank formed the view that the merger of ICICI with ICICI Bank would be the optimal strategic alternative for both the entities, and would create the optimal legal structure for the ICICI group's universal banking strategy. Further, the merger would enhance value for ICICI shareholders through the merged entity by low-cost deposits, greater opportunities for earning fee-based income and the ability to participate in the payments system and provide transaction-banking services. Consequently, ICICI Bank was promoted in 1994 by ICICI Limited, an Indian financial institution, and was its wholly-owned subsidiary. The general question of the study intended to provide the answer to the $\mathrm{n}$ impact of HRD practices on managerial effectiveness to ensure the employees engagement praise and job involvement in the ICICI bank. Therefore, it can be summarized as -What are the significant issues of HRD practices that have impact on employee's managerial effectiveness in banks.

\section{Objectives of the study}

$>$ To investigate the various HRD practices like; Role development, Performance appraisal, Performance counseling, Potential appraisal, Career planning and development, Training, Organizational development in Indian ICICI bank and employees engagement practice.

$>$ To investigate the impact of HRD practices on managerial effectiveness ICICI bank

> To assess the relationship between HRD practices (Role development, Performance appraisal, Performance counseling, Potential appraisal, Career planning and development, Training, Organizational development) with managerial effectiveness

Most importantly, this study explores the relationship between specialization variables (behavior, skill/knowledge, commitment, performance appraisal, motivation, and training) and managers willingness to fluctuate his/her attitude to enhance the job involvement of the employees 


\section{Data source and methodology}

The present study was carried out in ICICI bank branches in Chennai, with a purpose to investigate HRD practices that exist in ICICI banks and their impact on the employees managerial effectiveness to facilitate the employees engagement practice and job involvement. The study was conducted in Chennai. 100 Sample was collected with minimum three years of experience in the same organization. To measure HRD practices and managerial effectiveness standard questionnaire was used. Later the data was coded and fed into computers using SPSS (Statistical Package for Social Sciences) as software for data analysis. The collected data was processed and analyzed with the help of SPSS package; Descriptive Analysis, Multinominol Regression were used for proving the hypothesis and predicting the basis of analysis.

\section{Analysis}

Logistic regression analysis was used to identify the relationships between dependent variable (resource substitution behavior) and independent variables (recreation specialization, socioeconomic characteristics, and constraints). The logistic regression model is shown as the following form:

\section{$\ln (\mathbf{p} / \mathbf{1}-\mathbf{p})=\beta \mathbf{\beta o}+\boldsymbol{\beta i X i}$}

where $\mathrm{p}=$ the probability of resource substitution behavior; $(\mathrm{p} / 1-\mathrm{p})=$ odds of resource substitution

behavior; $\beta \mathrm{o}=$ constant; $\mathrm{Xi}=$ vector of independent variables; $\beta \mathrm{i}=$ parameter estimate for the ith independent variable. The logistic regression is powerful in its ability to estimate the individual effects of continuous or categorical independent variables on categorical dependent variables (Wright 1995).

The multinomial logistic regression model used is generally effective where the dependent variable is composed of a polytomous category having multiple choices. The basic concept was generalized from binary logistic regression (Aldrich \& Nelson 1984, Hosmer\&Lemeshow 2000). In a multinomial logistic regression model, the estimates for the parameter can be identified compared to a baseline category (Long, 1997). In this study, having no willingness to substitute was specified as the baseline category. The multinomial logistic regression model with a baseline category would be expressed as follows:

$\log (\pi \mathrm{i} / \pi \mathrm{I})=\alpha \mathbf{i}+\beta \mathrm{ix}, \mathrm{i}=1, \ldots \ldots, \mathrm{I}-1$.

The logistic model uses the baseline-category logits with a predictor $\mathrm{x}$. This multinomial logistic regression model can be a useful tool for modeling where the dependent variable is a discrete set of more than two choices (Agresti, 1996). The multinomial logistic regression model used in this study estimates the effect of the individual variables on the engagement practice and job involvement of the employees in ICICI bank

\section{Results}

Significant portion of Mangers were (73.2\%) were male. About 18 percent of the HR Mangers said their annual household income was 8 lakhs or above per annum, and 47.4 percent reported an annual household income between 5 to 6 lakhs. Most HR managers (58\%) were between the ages of 31 and 50. Most (90.3\%) indicated a willingness to participate to enhance the job involvement of the employees. Only 10.2 percent of the HR Mangers reported that there was no innovative plan rather than routine procedure. Most respondents (89.8\%) said that there was strong influence of mangers attitude to engage employees. In more detail, 48.7 percent of the managers said incentives and intensive training had more influence; 16.2 percent said salary. Most respondents $(59 \%)$ also reported there were other recreational activities that would provide the same level of satisfaction and enjoyment and involvement to the employees. The most frequently identified substitutable involvement activities for employees were salary hike $(40.1 \%)$, interpersonal care of mangers $(32.6 \%)$, Training $(20.3 \%)$, clear surveillance $(11.0 \%)$. The final model specification of was statistically significant $(\chi 2=$ 85.817; $\mathrm{p}<0.0001)$. From the results of the multinomial logistic regression analysis in the model, managers attitude and incentives positively influence the job involvement and the persistent surveillance negatively influence the job involvement of the employees of the ICICI bank employees in the study area.

Table: Results of the Multinomial Logistic Regression in the Final Model showing Significant Effects on HR managers function on job involvement of bank employees of ICICI(Final model included only significant variables at $\mathbf{. 0 5}$ level)

\begin{tabular}{|l|l|l|l|l|l|l|}
\hline Variables & Coefficient & S.E. & Wald & Df & Sig. & Exp(B) \\
\hline Job Involvement & 2.561 & 89.7 & 1.664 & 1 & 0.005 & 0.112 \\
\hline Salary & 0.992 & 5.749 & 1.021 & 1 & 0.002 & 2.185 \\
\hline Incentives and promotion & 1.912 & 1.639 & 2.927 & 1 & 0.001 & 1.442 \\
\hline Good-coordination with colleagues & 2.843 & 4.918 & 3.818 & 1 & 0.003 & 0.213 \\
\hline Appreciation of the officers & 2.402 & 4.071 & 2.858 & 1 & 0.078 & 0.011 \\
\hline
\end{tabular}




\begin{tabular}{|l|l|l|l|l|l|l|}
\hline Capacity building training & 2.674 & 8.148 & 1.242 & 1 & 0.072 & 1.55 \\
\hline Admissible deadline and work load & 0.065 & 0.033 & 1.979 & 1 & 0.003 & 1.068 \\
\hline Liberty to take decision in job & 0.017 & 0.009 & 2.471 & 1 & 0.002 & 1.017 \\
\hline Recreation activities & 0.01 & 0.007 & 1.147 & 1 & 0.143 & 0.99 \\
\hline Presence mind of HR Managers & 0.143 & 1.541 & 1.68 & 1 & 0.005 & 1.6 \\
\hline Commitment of HR mangers & 0.965 & 2.478 & 2.005 & 1 & 0.005 & 0.612 \\
\hline
\end{tabular}

\section{Discussion}

Multinomial Logistic regression analysis revealed clear pattern of presence grids for each explanatory variable involved in model. Enter method was applied for all ten variables, the variables which were strongly correlated $(\mathrm{P}>0.6)$, Based on quality of information, ten variables were utilized to develop a better model fit and also for development of final equation for character farming, The -2 Log Likelihood value and Nagelkerke R2 were 71.29 and 0.519 respectively, indicating improvement of model fit with inclusion of the above variables and a combined effect of the variables in predicting probability of occurrence. Hosmer and Lemeshow goodness-of-fit test indicated that the obtained model did not differ significantly from null model or expected fit $(\chi 2=6.511, \mathrm{p}=0.21)$. Overall correct prediction rate of the model was $74.2 \%$. Prediction rate for true positives (presence - 1) was 80.2 and it was $58.5 \%$ for true negatives (not present -0 ). The best cut-off level that optimized sensitivity and specificity was at 0.5 .Final analysis at this cut-off point had ten explanatory variables were used to develop final equation,. The explanatory variables used in the final equation collectively accounted for $82 \%$ for the explained variables for character framing $(R 2=0.829)$

To better understand attitude of HR managers to ensure the engagement practice of the employees, this study used predictors such as specialization, socio-demographic, and constraint variables. Among them, recreation specialization was expected to be an important factor to affect recreationists' future behavior in outdoor recreation research as well as management issues. As such, this study examined the relationship between managers attitude and three kinds of recreation specialization dimensions, which were divided into behavioral (behavior), cognitive (skill/knowledge), and affective (commitment). As shown in this study, resource substitutability by HR managers can be measured by the level of a willingness to substitute the attitude and operation. Results showed HR mangers effectiveness was around 90 percent and that only 10 percent of the managers were not effectively influenced the engagement practice. The result was consistent, which showed that if employees could not effectively stick to job involvement, most of the HR mangers (70\%) in recreational were not willing to substitute other attitude. Since there have been only a few previous studies dealing with resource substitutability in outdoor recreation activities, we cannot assume our results can be compared directly with previous studies. However, we know that many studies regarding substitution have been concentrated on recreationists' willingness to substitute under some hypothetical condition (substitutability) rather than actual behavioral change in their resources or activities. The multinomial logistic regression model provided sufficient evidence that HR managers attitude was closely associated with an individual's willingness to enhance the job involvement which means that interpersonal skills, ensure the good environment, salary hike, incentives influence the job involvement behavior of the employees in the studied bank. The results showed how much specialization, constraints, and demographic variables are related to job involvement. The multinomial logistic regression using a classification method for the dependent variable would provide a more satisfactory solution compared to other analysis techniques because it not only requires strict assumptions, but enables a direct interpretation of the relationship between independent variables and the dependent variable (Press \& Wilson 1978).

\section{Conclusion}

The examination of the HR mangers effective function on the job involvement attitude of the employees in the ICICI bank indicated that the interpersonal attitude and maintenance of effective environment in the bank have strongly influence job involvement attitude of the employee, This effort involves how the three dimensions of recreation specialization are associated with recreationists' involvement, motivation, and social groups. This study as pre-research for future research will help various stakeholders (e.g., voluntary association groups, national or regional agencies, and other related groups) and researchers understand recreationists' substitution behavior. Additionally, the results of this study suggested that HR managers specialization level (behavioral, cognitive, and affective) is closely related to their future behavior pattern, such as recreation substitutability, job involvement enhance the productivity of the employees which ultimately results in overall development in the service delivery, in the changing context in the banking service urged the managers to make compatibility between optimum utilization of the productivity of the employees and the quality of service in this context managers strategy to ensure the job involvement of the employees very essential provide the good quality of services in the banking industries. 


\section{References}

[1.] Abraham E.S.J. (1988), "HRD Climate in Banks", in A.K. Khandelwal (eds.), HRD in Banks, Oxford and IBH Publishing Co., New Delhi, pp. 49-65.

[2.] Agarwal Ashok and UdaiPareek (1997), "The Role of HRD in Service Sector", in D.M. Silvera, C.M. Srivastava, R. Vidyasagar and T.V. Rao (eds.), HRD in the New Economic Environment; Tata McGraw Hill, Publishing Company, New Delhi, pp. 190-198.

[3.] Arthur, J.B. 1994. Effects of human resource systems on manufacturing performance and turnover.Academy of Management Journal. 37:670-687

[4.] Kao, B. Prabhakar (1993), "Personnel Management and Industrial Relations in Banking industry", Mittal Publications, New Delhi, pp. 161-176. 44.

[5.] Kool ,Reeta and Saksena , N. K. (1989). Leadership styles and its effectiveness among Indian executives. Indian of applied psychology, 26 (1) 9-15

[6.] Sharma B.R. (1988), "HRM in Banking Industry", in A.K. Khandelwal (eds.), HRD in Banks, Oxford and IBH Publishing Co., New Delhi, pp. 32-48,45.

[7.] Wang, Greg G; National HRD a new paradigm or re invention of the wheel : Journal of European Industrial Training, 2008 , Vol. 32 Issue 4, p303-316, 14p

[8.] Yukl ,Bass and McCali, Combardo (1989) .Managerial Leadership : A review of theory and research. Journal of management , 15 (2) , 251-289. 